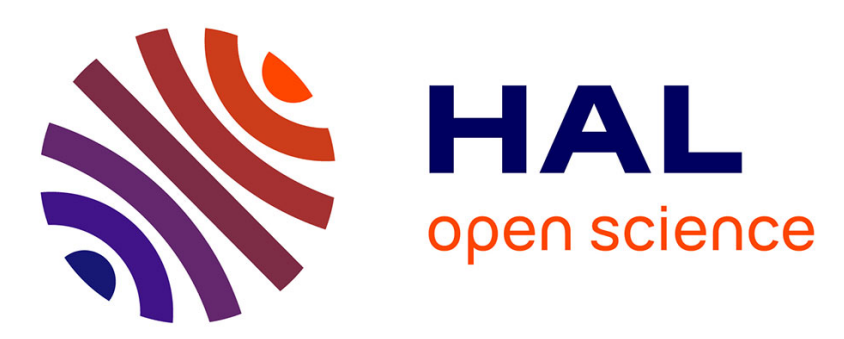

\title{
Balancing mixed-model assembly lines: A computational evaluation of objectives to smoothen workload
}

\author{
Simon Emde, Nils Boysen, Armin Scholl
}

\section{To cite this version:}

Simon Emde, Nils Boysen, Armin Scholl. Balancing mixed-model assembly lines: A computational evaluation of objectives to smoothen workload. International Journal of Production Research, 2010, 48 (11), pp.3173-3191. 10.1080/00207540902810577 . hal-00580109

\section{HAL Id: hal-00580109 \\ https://hal.science/hal-00580109}

Submitted on 26 Mar 2011

HAL is a multi-disciplinary open access archive for the deposit and dissemination of scientific research documents, whether they are published or not. The documents may come from teaching and research institutions in France or abroad, or from public or private research centers.
L'archive ouverte pluridisciplinaire HAL, est destinée au dépôt et à la diffusion de documents scientifiques de niveau recherche, publiés ou non, émanant des établissements d'enseignement et de recherche français ou étrangers, des laboratoires publics ou privés. 


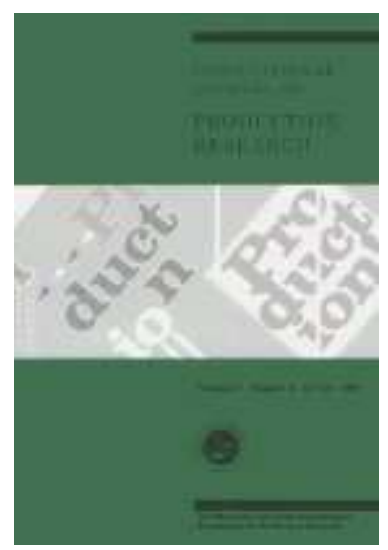

\section{Balancing mixed-model assembly lines: A computational evaluation of objectives to smoothen workload}

\begin{tabular}{|r|l|}
\hline Journal: & International Journal of Production Research \\
\hline Manuscript ID: & TPRS-2008-IJPR-0796.R1 \\
\hline Manuscript Type: & Original Manuscript \\
\hline Author: & 04-Feb-2009 \\
\hline & $\begin{array}{l}\text { Submitted by the } \\
\text { Managen, Nils; Fist of Authors: } \\
\text { Scholl, Armin; Friedrich-Schiller-Universität Jena, Management } \\
\text { Science }\end{array}$ \\
\hline Keywords: & $\begin{array}{l}\text { ASSEMBLY, ASSEMBLY LINE BALANCING, COMBINATORIAL } \\
\text { OPTIMIZATION, SEQUENCING }\end{array}$ \\
\hline Keywords (user): & workload smoothing \\
\hline
\end{tabular}

\section{今scholaronE \\ Manuscript Central}




\title{
Balancing mixed-model assembly lines: A computational evaluation of objectives to smoothen workload
}

\author{
Simon Emde ${ }^{a, *}$, Nils Boysen ${ }^{a}$, Armin Scholl $^{b}$ \\ ${ }^{a}$ Friedrich-Schiller-Universität Jena, Lehrstuhl für Operations Management, \\ Carl-Zeiß-Straße 3, D-07743 Jena, Germany, \\ \{simon.emde,nils.boysen\}@uni-jena.de \\ * Corresponding author, phone +493641/943104. \\ ${ }^{b}$ Friedrich-Schiller-Universität Jena, Lehrstuhl für Betriebswirtschaftliche \\ Entscheidungsanalyse, Carl-Zeiß-Straße 3, D-07743 Jena, Germany, \\ a.scholl@wiwi.uni-jena.de
}

\begin{abstract}
Mixed-model assembly lines are widely used in a range of production settings, such as the final assembly of the automotive and electronics industries, where they are applied to mass-produce standardized commodities. One of the greatest challenges when installing and reconfiguring these lines is the vast product variety modern mixed-model assembly lines have to cope with. Traditionally, product variety is bypassed during mid-term assembly line balancing by applying a joint precedence graph, which represents an (artificial) average model and serves as the input data for a single model assembly line balancing procedure. However, this procedure might lead to considerable variations in the station times, so that serious sequencing problems emerge and work overload threatens. To avoid these difficulties different extensions of assembly line balancing for workload smoothing, i.e., horizontal balancing, have been introduced in the literature.

The paper on hand presents a multitude of known and yet unknown objectives for workload smoothing and systematically tests these measures in a comprehensive computational study. The results suggest that workload smoothing is an essential task in mixed-model assembly lines and that some (of the newly introduced) objectives are superior to others.

Keywords: Mixed-model assembly lines; assembly line balancing; sequencing; workload smoothing
\end{abstract}




\section{Introduction}

Assembly lines are production systems in which parts are added to a product sequentially by employing a transportation system (usually a conveyor belt) which moves the workpieces successively through productive units, called stations. They are applied to mass-produce standardized commodities, e.g., in the automotive and electronics industries. While single model lines were the norm in the early days of industrial manufacturing, nowadays multi-skilled workers and automated tool-swaps enable the assembly of a multitude of different variants of a common base product in consecutive cycles with negligible setup cost and time. How far flexibility in these mixed-model assembly lines has progressed can be seen by looking at the number of options offered by today's car manufacturers, amounting to up to $10^{32}$ different models produced on the same assembly line (Meyr, 2004).

Mixed-model assembly lines require the solution of two major planning tasks (see Meyr (2004) and Boysen et al. (2007a) for surveys on the complete hierarchy of line planning):

- Whenever an assembly line is initially installed or reconfigured, the assembly line balancing (ALB) problem is to be solved, which partitions the assembly work among the stations while regarding precedence constraints among tasks and a common cycle time with respect to some objective. To cope with multiple models to be produced on the line a joint precedence graph representing an (artificial) average model is introduced, which serves as the input data for a single model ALB procedure (see Boysen et al., 2006).

- Additionally, a short-term sequencing problem is to be solved, which decides on the succession of models to be launched down the line during a day or production shift. Due to the fact that tasks can take differing amounts of time depending on which model they are performed on, the sum of operating times of the tasks assigned to a station can fluctuate greatly. For example, the task "mount sunroof" might take longer for a model with an electrically powered sunroof compared to a model with a manually operated one, or is absent when no sunroof is required at all. If there are several models with electric sunroofs scheduled in a row the respective station may become overloaded. Such work overload must be compensated, e.g., by utility workers, causing additional cost (Tsai, 1995). See Boysen et al. (2009) for a detailed survey on assembly line sequencing.

Although there is a great temporal distance between balancing and sequencing decisions, the two planning steps are anything but independent. By partitioning the workload between stations, assembly line balancing determines the station time per model. Thus, depending on the line balance differences in a station's workload may vary to a greater or smaller extent, making it potentially impossible for a sequencing procedure to determine "good" model sequences. Consequently, in addition to traditional balancing objectives, e.g., the minimization of the number of stations (SALBP-1), work overload resulting from model sequencing also becomes a quality criterion for line balancing. To account 
for this interdependency, line planning needs to integrate both essential planning tasks. In general, there exist three alternatives:

Successive Planning: In its traditional form, interdependencies between both tasks are neglected and planning is executed in two independent steps. Obviously, the resulting simplification of line planning incurs more restricted sequencing problems typically leading to higher short-term work overloads.

Simultaneous planning: The other extreme is to handle both planning tasks jointly in a simultaneous balancing and sequencing problem. Respective approaches are provided by McMullen and Frazier (1998), Kim et al. (2000a,b, 2006), Miltenburg (2002), Sawik (2002) as well as Bock et al. (2006). However, in many settings, these approaches suffer from two serious drawbacks. First, the resulting planning models contain an enormous number of decision variables and constraints, so that complexity impedes an efficient solution. Prolonged run-times of algorithms and/or a (comparatively) low solution quality are the consequences. An even more serious drawback is that both planning tasks have a completely different time frame. At the point in time where mid-term line balancing is executed short-term model-mixes per shift are hard to anticipate accurately. Thus it heavily depends on the forecast accuracy (and therefore the length of the planning horizon) whether a simultaneous procedure indeed increases planning quality compared to successive planning.

Anticipation: As the planning horizon of ALB is typically comparatively long, i.e., usually ranging from a few years when installing a new line (see Boysen et al., 2007a) to several months or weeks when reconfiguring an existing line, it seems generally more practical to decompose the total decision problem into separate yet coordinated planning steps. Respective line balancing approaches aim at anticipating the consequences on model sequencing in a more aggregated fashion instead of based on detailed model-mixes per shift. For instance, procedures known as horizontal balancing (see Merengo et al., 1999) introduce an additional objective for line balancing, which aims at smoothing the workload per station over all models. Note that a model-mix forecast is also required for such an anticipation alternative. However, merely the average model-mix over multiple sequencing periods, i.e., all shifts during the life-time of a line balance, is required and it is a well known phenomenon that aggregated forecasts are more precise than disaggregated ones (see, e.g., Chopra and Meindl, 2006).

It is the aim of this paper to identify suitable forms of anticipation during assembly line balancing, which are able to identify robust line balances resulting in a reduction of short-term work overloads. For this purpose, a comprehensive computational study is conducted, which, first, determines line balances applying different forms of anticipation and then tests these line balances by determining the resulting work overload for different daily short-term model-mixes. Although some forms of anticipation have already been introduced in the literature, these alternatives have not been tested systematically, yet. Moreover, we introduce additional forms of anticipation and investigate the influence of product-variety as well as forecast errors. 
For this purpose, the remainder of the paper is organized as follows. In Section 2 the different forms of anticipation and workload smoothing are introduced. Therefore, we review the existing literature on this topic and systematically derive novel forms of anticipation. Then, the setup of our computational study is described in detail (Section 3). Section 4 presents the results and Section 5 concludes the paper.

\section{Workload smoothing}

If sequencing issues are to be observed in ALB by an appropriate anticipation mechanism, two choices need to be taken: (i) an appropriate workload smoothing criterion is to be identified and (ii) the selected anticipation criterion needs to be related to the primary objective of ALB, which is usually to minimize the number of stations or workers required.

With regard to the first choice, an objective is required which both adequately estimates the actual work overload and can be easily derived from the original input data of ALB. In the literature, different objectives are proposed to meet these two requirements. Using the notation defined in Table 1, Table 2 enumerates possible objectives.

Columns A through $\mathrm{C}$ contain objective functions belonging to horizontal balancing, whereas the objectives of column D belong to vertical balancing according to the nomenclature of Merengo et al. (1999). In horizontal balancing the objectives aim at a workload smoothing per station $k$ over all models $p \in P$, so that the deviation of the actual processing time per model and station $\tau_{p k}$ from some target station time is minimized. Target station times are (A) the cycle time, (B) the average processing time of a model $p$ per station and $(\mathrm{C})$ the average processing time of all models per station, respectively. In vertical balancing (Column D), the objectives aim at evenly distributing the workload among the stations, so that the average station time is to be adjusted towards the average processing time of all models per station. In each column, different functions can be utilized to measure the distances, which additionally can either be unweighted or weighted by the proportion of the respective product in the model-mix $b_{p}$. 


\begin{tabular}{|c|c|c|c|c|c|}
\hline & & $\begin{array}{l}\text { Processing time of } \\
\text { model vs. cycle time (A) }\end{array}$ & $\begin{array}{l}\text { Processing time of model } \\
\text { vs. } \varnothing \text { processing time of } \\
\text { model per station (B) }\end{array}$ & $\begin{array}{l}\text { Processing time of } \\
\text { model vs. } \varnothing \text { processing } \\
\text { time of all models per } \\
\text { station }(\mathrm{C})\end{array}$ & $\begin{array}{l}\varnothing \text { Station time vs. } \\
\varnothing \text { processing time of } \\
\text { all models per } \\
\text { station (D) }\end{array}$ \\
\hline \multirow{2}{*}{ 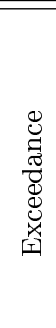 } & 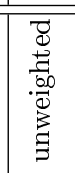 & $\begin{array}{c}\sum_{p, k} \max \left\{0, \tau_{p k}-c\right\} \\
\text { (1) }\end{array}$ & $\begin{array}{c}\sum_{p, k} \max \left\{0, \tau_{p k}-T_{p}\right\} \\
\text { (9) }\end{array}$ & $\begin{array}{c}\sum_{p, k} \max \left\{0, \tau_{p k}-\bar{T}\right\} \\
(17)\end{array}$ & $\begin{array}{c}\sum_{k} \max \left\{0, T_{k}^{*}-\bar{T}\right\} \\
(25)\end{array}$ \\
\hline & 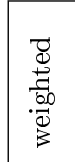 & $\begin{array}{c}\sum_{p, k} \max \left\{0, b_{p} \cdot\left(\tau_{p k}-c\right)\right\} \\
(2)\end{array}$ & $\begin{array}{c}\sum_{p, k} \max \left\{0, b_{p} \cdot\left(\tau_{p k}-T_{p}\right)\right\} \\
(10)\end{array}$ & $\begin{array}{c}\sum_{p, k} \max \left\{0, b_{p} \cdot\left(\tau_{p k}-\bar{T}\right)\right\} \\
(18)\end{array}$ & - \\
\hline \multirow{2}{*}{ 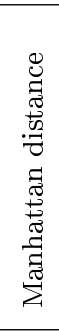 } & 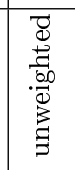 & $\sum_{p, k}\left|\tau_{p k}-c\right|$ & $\sum_{p, k}\left|\tau_{p k}-T_{p}\right|$ & $\begin{array}{c}\sum_{p, k}\left|\tau_{p k}-\bar{T}\right| \\
\quad(19)\end{array}$ & $\sum_{k}\left|T_{k}^{*}-\bar{T}\right|$ \\
\hline & 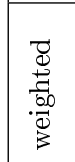 & $\begin{array}{c}\sum_{p, k} b_{p} \cdot\left|\tau_{p k}-c\right| \\
(4)\end{array}$ & $\begin{array}{c}\sum_{p, k} b_{p} \cdot\left|\tau_{p k}-T_{p}\right| \\
(12)\end{array}$ & $\begin{array}{c}\sum_{p, k} b_{p} \cdot\left|\tau_{p k}-\bar{T}\right| \\
(20)\end{array}$ & - \\
\hline \multirow{2}{*}{ 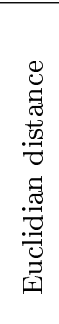 } & 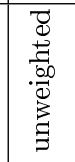 & $\sqrt{\sum_{p, k}\left(\tau_{p k}-c\right)^{2}}$ & $\sqrt{(13)}^{\sqrt{\sum_{p, k}\left(\tau_{p k}-T_{p}\right)^{2}}}$ & $\begin{array}{c}\sqrt{\sum_{p, k}\left(\tau_{p k}-\bar{T}\right)^{2}} \\
(21)\end{array}$ & $\begin{array}{c}\sqrt{\sum_{k}\left(T_{k}^{*}-\bar{T}\right)^{2}} \\
(27)\end{array}$ \\
\hline & 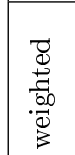 & $\begin{array}{c}\sqrt{\sum_{p, k}\left(b_{p} \cdot\left(\tau_{p k}-c\right)\right)^{2}} \\
(6)\end{array}$ & $\begin{array}{c}\sqrt{\sum_{p, k}\left(b_{p} \cdot\left(\tau_{p k}-T_{p}\right)\right)^{2}} \\
(14)\end{array}$ & $\begin{array}{c}\sqrt{\sum_{p, k}\left(b_{p} \cdot\left(\tau_{p k}-\bar{T}\right)\right)^{2}} \\
(22)\end{array}$ & - \\
\hline \multirow{2}{*}{ 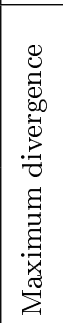 } & 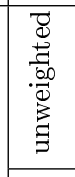 & $\begin{array}{c}\max _{p, k}\left\{\left|\tau_{p k}-c\right|\right\} \\
(7)\end{array}$ & $\begin{array}{c}\max _{p, k}\left\{\left|\tau_{p k}-T_{p}\right|\right\} \\
(15)\end{array}$ & $\begin{array}{c}\max _{p, k}\left\{\left|\tau_{p k}-\bar{T}\right|\right\} \\
(23)\end{array}$ & $\begin{array}{c}\max _{k}\left\{\left|T_{k}^{*}-\bar{T}\right|\right\} \\
(28)\end{array}$ \\
\hline & 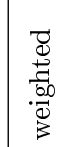 & $\begin{array}{c}\left.\max _{p, k}\left\{b_{p} \cdot \mid \tau_{p k}-c\right) \mid\right\} \\
(8)\end{array}$ & $\begin{array}{c}\left.\max _{p, k}\left\{b_{p} \cdot\left|\tau_{p k}-T_{p}\right|\right)\right\} \\
(16)\end{array}$ & $\begin{array}{c}\max _{p, k}\left\{b_{p} \cdot\left|\tau_{p k}-\bar{T}\right|\right\} \\
(24)\end{array}$ & - \\
\hline
\end{tabular}

Table 2: Objective functions for workload smoothing

Once one of the smoothing functions is selected, it needs to be related to the original objective of ALB. In principle, any coupling mechanism of multi-objective optimization can also be applied to ALB. However, in the existing assembly line literature these objectives are either put in lexicographic order or unified to a unique objective function by applying objective-specific weighting factors. The latter approach especially suffers from the problem of determining suited weighting factors, which mirror the actual underlying relationship between (investment) cost of line balancing and cost caused by work overload in an adequate way. To avoid this problem, we restrict our computational study to 
the lexicographic case, where the most common balancing objective, the minimization of the number of stations (SALBP-1), is given top priority and workload smoothing is the secondary objective. This setting seems reasonable because, typically, due to the high level of automatization, investment cost for an assembly line are much higher than cost caused by daily work overload. Furthermore, SALBP-1 typically has many optimal solutions having the same number of stations, so that enough degrees of freedom remain to identify one of the optimal solutions which also optimizes the smoothing criterion.

Since the seminal work of Moodie and Young (1965) several papers have been presented which deal with workload smoothing. These papers can be subdivided into two groups. The first group provides specific line balancing procedures for a given workload smoothing criterion. The second group of workload smoothing literature deals with testing different smoothing criteria with regard to their ability in reducing work overload. We summarize the first group in Table 3, where the smoothing criterion applied (according to Table 2), the relation to the original ALB objective and the algorithmic approach are given. The abbreviations are borrowed from the ALB-classification of Boysen et al. (2007b):

HI heuristic improvement procedure

GA genetic algorithm

SA simulated annealing

DP dynamic programming

B\&C branch-and-cut

LEX lexicographic order
HS start heuristic for initial solution

TS tabu search

ACO ant colony optimization

B\&B branch-and-bound

WF weighting factor

The multitude of different ALB approaches incorporating workload smoothing is an indicator of its practical relevance in real-world applications. Nonetheless, apparently only about half of the criteria of Table 2 have ever been actively researched. Also, a suitable optimization approach for a given smoothing criterion is merely one side of the coin. Moreover, the appropriateness of the different smoothing approaches also needs to be investigated. Up to now, this problem was merely tackled by Domschke et al. (1996, summarized in Scholl, 1999, Ch. 3.2.2.3) and Bukchin (1998).

Domschke et al. (1996) present a simulation study similar to our setting. The smoothing criteria (1), (12), (14), (15) and (27) from Table 2 are used as a secondary objective to determine line balances. The resulting work overloads for these line balances are then calculated by a mixed-model sequencing approach for different daily model-mixes. As a result from their simulation setting, criterion (1) seems especially suited in avoiding work overloads. Bukchin (1998) defines a different simulation setting. Here, random line balances are generated for which a significant positive correlation between the actual work overload and criterion (12) is identified. However, in contrast to these previous studies the paper on hand tests all smoothing criteria of Table 2 and, additionally, investigates the influences of product variety and forecast errors. 


\begin{tabular}{llll} 
Publication & $\begin{array}{l}\text { smoothing } \\
\text { terion }\end{array}$ & $\begin{array}{l}\text { cri- } \\
\text { ALB }\end{array}$ & algorithm \\
\hline Agnetis (1995) & $1,25,27$ & LEX & DP \\
Ajenblit und Wainwright (1998) & 15 & WF & GA \\
Bhattacharjee and Sahu (1987) & 5 & LEX & HS \\
Decker (1993) & 15 & LEX & HI \\
Domschke et al. (1996) & $1,12,14,15,27$ & LEX, WF & B\&B \\
Kim et al. (2006) & 20 & LEX & GA \\
Matanachai and Yano (2001) & $11,19,26$ & WF & HI \\
McMullen and Frazier (1997, 1998), McMullen & 5 & WF & GA \\
and Tarasewich (2003, 2006) & & & \\
Merengo et al. (1999) & 27 & LEX & HS, HI \\
Moodie and Young (1965) & 27 & LEX & HI \\
Pastor and Corominas (2000) & 26 & LEX & TS \\
Pinnoi and Wilhelm (1997) & 7 & LEX & B\&C \\
Ponnambalam et al. (2000) & 27 & WF & GA \\
Rachamadugu and Talbot (1991) & 26,27 & LEX & HI \\
Rekiek et al. (2001, 2002) & 5 & LEX & GA \\
Sabuncuoglu et al. (2000) & 27 & WF & GA \\
Sarker and Shanthikumar (1983) & 28 & LEX & HI \\
Sparling and Miltenburg (1998) & 2,20 & LEX & HI \\
Suresh and Sahu (1994), Suresh et al. (1996) & 27 & LEX & GA, SA \\
Thomopoulos (1970) & 12 & LEX & HI \\
Ugurdag et al. (1997) & 27 & LEX & HI \\
Vilarinho and Simaria (2002, 2006) & 16 & LEX & SA, ACO \\
\hline
\end{tabular}

Table 3: An overview on workload smoothing in the literature on assembly line balancing

\section{Setup of the computational study}

The basic idea of our study is to determine different line balances with the 28 smoothing criteria defined in Table 2. Thus, for each test instance, 28 different ALB solutions and an additional reference ALB solution without workload smoothing (successive planning) are determined. Then, we randomly draw different daily model-mixes (sequencing instances) each of which is to be solved by a mixed-model sequencing approach. The resulting work overload is our final measure to compare the workload smoothing criteria with regard to their ability in reducing short-term work overloads. Moreover, to gain further insights we aim at comparing workload smoothing in different settings, namely high, medium and low product variety as well as high, medium and low forecast uncertainty, respectively.

To describe the detailed setting of our computational study, the following three sections elaborate on instance generation (Section 3.1), additional assumptions on the underlying assembly system (Section 3.2) and the applied algorithms to solve the respective optimization problems (Section 3.3).

\subsection{Instance generation}

Our test data is based on the 64 classic Talbot SALBP instances (Talbot et al., 1986), which can be downloaded from http://www.assembly-line-balancing.de. For each instance the original single-model precedence graph is taken as the joint precedence graph of the set of assigned product models. It is the task of instance generation to split each joint precedence graph (i) into its contributing models, which determine the overall 
model-mix, and (ii) into some representative daily model-mixes, which build the input for the related sequencing problems.

ALB with the different smoothing criteria is to be tested in different settings, so that the number of models $|P|$ is varied and product variety is differentiated into high $(|P|=150)$, medium $(|P|=75)$ and low $(|P|=10)$. For each of these settings a specific line balance is to be determined, so that in total $64 \cdot 29 \cdot 3=5,568$ ALB problems have to be solved. The resulting line balances are passed over to the next step, where representative daily model-mixes are determined.

On the basis of a given parameter constellation, the input data is determined as follows: Each model $p \in P$ is assigned a random demand portion $b_{p}$ with $0<b_{p}<$ 1 and $\sum_{p \in P} b_{p}=1$. Then, a random task time $t_{j p}$ is determined for each model $p$ and each task $j \in V\left(0 \leq t_{j p} \leq 2 \cdot t_{j}\right.$ with $t_{j}$ being the task time of the original SALBP task) so that $\sum_{p \in P} b_{p} \cdot t_{j p}=t_{j} \forall j \in V$. The station length $l$ is equal for all stations and is set to $l=1.1 \cdot c$ and the total model demand per shift is expected to be $d=200$ units. Then, from the overall model-mix representative daily model-mixes have to be drawn. For this purpose, the demand vector $\mathbf{D}=\left(d_{1}, d_{2}, \ldots, d_{|P|}\right)$ is given by $d_{p}=\left\lfloor b_{p} \cdot d \cdot(1+(2 \cdot \operatorname{rnd}(0,1)-1) \cdot \alpha)\right\rceil \forall p \in P$ with $0 \leq \operatorname{rnd}(0,1) \leq 1$ being a uniformly distributed random number and $\lfloor\cdot 7$ representing rounding to the next integer. As a consequence, the demand for each model $p$ in each shift is uniformly distributed, ranging from $(1-\alpha) \cdot b_{p} \cdot d$ to $(1+\alpha) \cdot b_{p} \cdot d$.

Each line balance is to be tested with regard to its ability to reduce work overload facing high $(\alpha=1.0)$, medium $(\alpha=0.5)$ and low $(\alpha=0.1)$ forecast uncertainty. Moreover, multiple daily $(Z=20)$ model-mixes are to be tested to compute average performance, so that in total $5,568 \cdot 3 \cdot 20=334,080$ sequencing problems are to be solved. The total run-time to solve this enormous number of optimization problems exceeded 2 months on an x86 PC with an Intel Core 2 Quad Q9550 2.8 GHz CPU, with all algorithms being implemented in Borland Delphi 2006.

\subsection{Assumptions on the assembly system}

To model assembly line operations and to determine the detailed work overload some assumptions on the underlying assembly system have to be introduced. From the ALB point of view, we assume an assembly system in line with the basic assumptions of SALBP (see Baybars, 1986, Becker and Scholl, 2006), so that a single paced line without buffers and any kind of paralleling or assignment constraints is presupposed. As the original objective of ALB, we aim at minimizing the number of stations, so that the underlying assembly system can be represented by the basic ALB problem SALBP-1.

Further assumptions on the assembly system are required to determine work overload caused by different model sequences. Therefore, the following additional premises hold for our hypothetical assembly system (see Boysen et al., 2009):

- Working across the stations' boundaries is not possible (closed, non-overlapping stations).

- The constant velocity of the conveyor belt is normalized to one. 
- The operators return with infinite velocity to the next workpiece. This is an adequate simplification whenever the conveyor speed is much slower than the walking speed of workers, as is typically the case in practice.

- Work overload is measured by the time or space necessary to complete all work in excess of the respective station's right border (without compensation).

- Work overload has no impact on the succeeding station. Thus, the model assumes that the work overload is either compensated by a utility worker or by accelerating processing velocity.

With these premises on hand, a mixed-model sequencing approach can be applied to determine a launch sequence of models which minimizes work overload. Such a mixedmodel sequencing approach schedules the models in detail at each station and cycle, by explicitly taking into account processing times, worker movements and station borders. According to a recent classification of model sequencing approaches provided by Boysen et al. (2009) the basic sequencing problem assumed here can be characterized by the tupel $M S[\mid]$. Model formulations and solution procedures for this basic mixed-model sequencing problem are provided by Yano and Rachamadugu (1991), Bard et al. (1992) and Scholl et al. (1998).

\subsection{Applied optimization approaches}

The optimization is divided into an ALB part and a sequencing part.

First, the well-known branch-and-bound procedure SALOME (Scholl and Klein, 1997, 1999 ) is used to determine the optimum number of stations $m^{*}$ for the ALB problem (SALBP-1). This solution is neither horizontally nor vertically balanced and serves as the benchmark for the improvement of the smoothing criteria. Then, to carry out the horizontal balancing, SALOME was adapted to incorporate secondary smoothing objectives. An in-depth explanation of the original algorithm would be out of the scope of this paper, so that exclusively the alterations required for workload smoothing are explained.

The general idea is to generate all feasible solutions to the ALB problem given the station count $m^{*}$ established in the previous step and the given cycle time $c$. Of these, the one with the best secondary objective value is chosen. The algorithm is a stationoriented branch-and-bound procedure, meaning that in each branching step alternative subproblems are defined by complete station loads for the next empty station. The problems are continuously subdivided, creating a multilevel enumeration tree which contains every possible solution to the given instance. In each node, a set of seven lower bounds on the number of stations is calculated and compared to the desired number of stations $m^{*}$ (see Scholl and Klein, 1997). If the lower bound is greater, the node is fathomed. Of the logical tests, only the Simple Permutation Rule, the Task Time Incrementing Rule and Prefixing can be used to fathom nodes (see Scholl and Klein, 1997). All other tests that SALOME originally employs potentially eliminate branches that lead to solutions with a station count equal to $m^{*}$, therefore they cannot be used here. 
The number of feasible line balances grows exponentially with problem size. Even SALBP-1 that the unmodified SALOME solves by finding just a single optimal solution is NP-hard; finding all solutions with $m^{*}$ stations can take a considerable amount of time. It is therefore desirable to prune the enumeration tree not only with regard to capacity oriented goals but to also ignore parts of the search space where no improvement with regard to the secondary objective can be made. For this purpose, a new lower bound is proposed, whose basic idea can easily be adapted to any of the 28 smoothing criteria. All criteria of Table 2 aim at minimizing the deviations of station times from some target value, like the cycle time $c$ in Column A. Relaxing the indivisibility restriction of the tasks, we can assume a perfectly smooth distribution of station times by dividing the yet unassigned workload $W L_{p}(i)$ for a model $p$ on tree level $i$ by the number of stations yet to be loaded $m^{*}-i$. Since station loads cannot be any smoother than this, actual deviations from the target value can never be greater than the lower bound. For example, for criterion (1) the lower bound on tree level $i$ is defined by:

$$
L B(1)=\sum_{p \in P} \sum_{k=1}^{i} \max \left\{0, \tau_{p k}-c\right\}+\sum_{p \in P} \max \left\{0,\left\lceil\frac{W L_{p}(i)}{m^{*}-i}\right\rceil-c\right\}
$$

Lower bound $L B(1)$ amounts to the sum of the cycle time exceedance that has occurred in the stations already loaded (first term), plus the exceedance over cycle time $c$ that would occur if the yet unassigned workload $W L_{p}(i)$ would be equally split among $m^{*}-i$ remaining stations (second term), where the average workload can be rounded up due to integer task times of ALB. The same basic idea can easily be adjusted for any other smoothing criterion.

Concerning solution quality, the original SALOME used to determine the optimal number of stations $m^{*}$ could solve all instances to optimality in very short time. The modified SALOME used for horizontal balancing could solve $54.89 \%$ of the instances to (proven) optimality within a given time frame of 900 CPU-seconds for ALB.

Lastly, to solve the sequencing problem, a simulated annealing algorithm similar to that proposed by McMullen and Frazier (2000) is used. Given a total demand of $d$ units in a given shift, the solution is represented as a sequence vector $s=\left(s_{1}, \ldots, s_{d}\right)$ where each position $s_{t}(t=1, \ldots, d)$ contains the model $p \in P$ to be assembled in cycle $t$. The initial solution is arbitrarily generated and neighboring solutions are reached by choosing two positions randomly and swapping the corresponding values. The difference between the work overload of the new $\left(W O_{\text {new }}\right)$ and the current $\left(W O_{\text {cur }}\right)$ solution is calculated as $\Delta=100 \cdot \frac{W O_{\text {new }}-W O_{\text {cur }}}{W O_{\text {cur }}}$. The current solution is replaced by the new one if $e^{-\Delta / T_{k}}>\operatorname{rnd}(0,1)$, with $T_{k}$ being the current temperature and $0 \leq \operatorname{rnd}(0,1) \leq 1$ being a uniformly distributed random number. The initial temperature $T_{1}$ is set high enough to accept all transitions in the first phase. Given the current temperature $T_{k}$, the new temperature $T_{k+1}$ is determined by $T_{k+1}=T_{k} /\left(1+\beta \cdot T_{k}\right), \beta=\frac{T_{1}-T_{F}}{\left(L_{B}-1\right) \cdot T_{1} \cdot T_{F}}$ (Lundy and Mees, 1986). The epoch length $L$ for the current temperature level is defined by $L=L_{B}+\left\lfloor L_{B} \cdot F\right\rfloor$ where $F=1-e^{-\left(f_{h}-f_{l}\right) / f_{h}}, f_{h}$ and $f_{l}$ are the highest and lowest work overloads measured during the last epoch, respectively, and $L_{B}=100$ is the initial epoch length (Cho et al., 2005). When the current temperature drops below $T_{F}=0.01$ the 
optimization is finished. Prior experimentation by McMullen and Frazier (2000) shows that the simulated annealing algorithm finds solutions to the sequencing problem very close to the optimum (deviations are reported to be less than one percent). Another study conducted by Boysen (2005) testing a similar algorithm confirms these results.

\section{Results}

In order to assess the quality of the solutions obtained by the different smoothing objectives the improvement over successive planning is measured by $\frac{W(S C)-W(S M)}{W(S C)}$, where $W(S C)$ and $W(S M)$ are the work overloads summarized over all $Z=20$ daily modelmixes for the successive planning and the smoothing approach, respectively, averaged over all instances.

The results are listed in Table 4. The average improvement as explained above is labeled Imp. in the table. Additional performance measures computed for each criterion are the number of instances where the respective criterion could find a solution with the least work overload compared to the other criteria (abbreviated by \# best) and the number of instances where the respective criterion reduces work overload to zero (\# zero). Note that these numbers can be greater than 64 because each of the original instances was tested with three product variety and three forecast uncertainty settings, resulting in a total number of $64 \cdot 3 \cdot 3=576$ instances. The values in square brackets denote the same performance measures but only for the instances that were solved to proven optimality.

The first conclusion to be drawn is that (irrespective of the specific criterion applied) workload smoothing considerably reduces short-term work overload compared to successive planning, where ALB disregards smoothing aspects. However, no single criterion outperforms all others with regard to all performance criteria, so that no single best criterion can be identified. In terms of improvement over the successive planning solution, smoothing criteria (1), (2) and (4) work best, although all criteria - with the notable exception of those concerned with vertical balancing in Column D - work well enough to improve balances by over or at least close to $30 \%$, as long as a distance measure other than maximum divergence is used. Vertical balancing, while still effective, is consistently less well suited to lowering work overloads than horizontal balancing (i.e., the criteria in Columns A through C). Concerning distance measures, exceedance seems to be just a tiny bit better than Manhattan and Euclidian distances which in turn are considerably better than maximum divergence. Leaving out the latter uncompetitive distance measure, the criteria of Column A outperform those of the other columns almost without exception, especially when taking into account that they found the best solution (\# best) far more often than the other criteria. This also holds true when comparing the number of instances where work overload could be avoided altogether (\# zero). Finally, with regard to the question whether unweighted or weighted smoothing criteria perform better no clear recommendation can be given as weighted criteria seem only slightly superior. Note that these observations are valid regardless of whether all instances or only the optimally solved ones are taken into consideration. 


\begin{tabular}{|c|c|c|c|c|c|}
\hline & & $\begin{array}{l}\text { Processing time of } \\
\text { model vs. cycle time } \\
\text { (A) }\end{array}$ & $\begin{array}{l}\text { Processing time of } \\
\text { model vs. } \varnothing \\
\text { processing time of } \\
\text { model per station }(\mathrm{B})\end{array}$ & $\begin{array}{l}\text { Processing time of } \\
\text { model vs. } \varnothing \\
\text { processing time of all } \\
\text { models per station (C) }\end{array}$ & $\begin{array}{l}\varnothing \text { Station time vs. } \varnothing \\
\text { processing time of all } \\
\text { models per station (D) }\end{array}$ \\
\hline \multirow{2}{*}{ 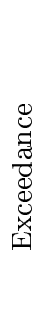 } & 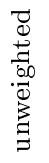 & $\begin{array}{c}\text { Imp.: } 32.78 \%[29.27] \\
\text { \# best: } 63[45] \\
\text { \# zero: } 24[18] \\
(1)\end{array}$ & $\begin{array}{c}\text { Imp.: } 30.82 \%[28.18] \\
\# \text { best: } 37[30] \\
\text { \# zero: } 15[12] \\
(9)\end{array}$ & $\begin{array}{c}\text { Imp.: } 30.30 \%[27.62] \\
\# \text { best: } 35[32] \\
\# \text { zero: } 12[12] \\
(17)\end{array}$ & $\begin{array}{c}\text { Imp.: } 27.94 \%[24.08] \\
\# \text { best: } 30[23] \\
\text { \# zero: } 12[12] \\
(25)\end{array}$ \\
\hline & 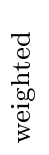 & $\begin{array}{c}\text { Imp.: } 33.82 \%[29.95] \\
\text { \# best: } 77[42] \\
\text { \# zero: } 21[15] \\
(2)\end{array}$ & $\begin{array}{c}\text { Imp.: } 31.09 \%[28.17] \\
\text { \# best: } 38[27] \\
\text { \# zero: } 15[12] \\
(10)\end{array}$ & $\begin{array}{c}\text { Imp.: } 31.25 \%[28.51] \\
\text { \# best: } 39[32] \\
\text { \# zero: } 12[12] \\
(18)\end{array}$ & \\
\hline \multirow{2}{*}{ 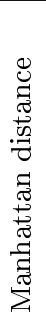 } & 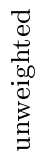 & $\begin{array}{c}\text { Imp.: } 31.70 \%[28.91] \\
\text { \# best: } 51[40] \\
\text { \# zero: } 18[18] \\
(3)\end{array}$ & $\begin{array}{c}\text { Imp.: } 30.76 \%[28.30] \\
\text { \# best: } 34[27] \\
\text { \# zero: } 15[12] \\
(11)\end{array}$ & $\begin{array}{c}\text { Imp.: } 30.14 \%[27.43] \\
\# \text { best: } 30[25] \\
\# \text { zero: } 15[12] \\
(19)\end{array}$ & $\begin{array}{c}\text { Imp.: } 26.05 \%[23.99] \\
\# \text { best: } 25[19] \\
\# \text { zero: } 12[12] \\
(26)\end{array}$ \\
\hline & 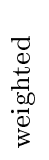 & $\begin{array}{l}\text { Imp.: } 32.88 \%[30.00] \\
\# \text { best: } 67[46] \\
\# \text { zero: } 18[15] \\
(4)\end{array}$ & $\begin{array}{c}\text { Imp.: } 31.16 \%[28.30] \\
\text { \# best: } 54[42] \\
\text { \# zero: } 15[12] \\
(12)\end{array}$ & $\begin{array}{c}\text { Imp.: } 31.09 \%[28.41] \\
\text { \# best: } 39[32] \\
\text { \# zero: } 15[12] \\
(20)\end{array}$ & - \\
\hline \multirow{2}{*}{ 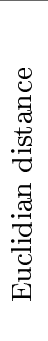 } & $\begin{array}{l}\vec{D} \\
\stackrel{D}{ \pm} \\
.00 \\
0 \\
\vdots \\
\Xi \\
\Xi\end{array}$ & $\begin{array}{c}\text { Imp.: } 30.80 \%[28.49] \\
\text { \# best: } 35[29] \\
\text { \# zero: } 12[12] \\
(5)\end{array}$ & $\begin{array}{c}\text { Imp.: } 30.85 \%[28.49] \\
\text { \# best: } 32[31] \\
\text { \# zero: } 12[12] \\
(13)\end{array}$ & $\begin{array}{c}\text { Imp.: } 30.72 \%[28.63] \\
\text { \# best: } 36[32] \\
\text { \# zero: } 12[12] \\
(21)\end{array}$ & $\begin{array}{c}\text { Imp.: } 25.65 \%[24.34] \\
\# \text { best: } 23[23] \\
\text { \# zero: } 12[12] \\
(27)\end{array}$ \\
\hline & 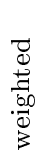 & $\begin{array}{c}\text { Imp.: } 29.80 \%[26.53] \\
\text { \# best: } 43[38] \\
\text { \# zero: } 12[12] \\
(6)\end{array}$ & $\begin{array}{c}\text { Imp.: } 29.33 \%[25.45] \\
\text { \# best: } 35[33] \\
\text { \# zero: } 12[12] \\
(14)\end{array}$ & $\begin{array}{c}\text { Imp.: } 29.60 \%[25.84] \\
\text { \# best: } 29[23] \\
\text { \# zero: } 9[9] \\
(22)\end{array}$ & \\
\hline \multirow{2}{*}{ 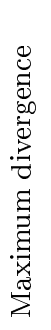 } & 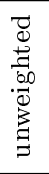 & $\begin{array}{c}\text { Imp.: } 19.96 \%[15.07] \\
\text { \# best: } 12[10] \\
\text { \# zero: } 3[3] \\
(7)\end{array}$ & $\begin{array}{c}\text { Imp.: } 25.89 \%[20.30] \\
\# \text { best: } 36[18] \\
\# \text { zero: } 16[9] \\
(15)\end{array}$ & $\begin{array}{c}\text { Imp.: } 24.51 \%[20.10] \\
\text { \# best: } 48[27] \\
\text { \# zero: } 20[12] \\
(23)\end{array}$ & $\begin{array}{c}\text { Imp.: } 26.75 \%[21.11] \\
\# \text { best: } 74[20] \\
\# \text { zero: } 15[12] \\
(28)\end{array}$ \\
\hline & 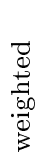 & $\begin{array}{l}\text { Imp.: } 20.00 \%[13.18] \\
\text { \# best: } 14[10] \\
\text { \# zero: } 6[6] \\
\quad(8)\end{array}$ & $\begin{array}{c}\text { Imp.: } 25.95 \%[18.98] \\
\text { \# best: } 51[20] \\
\text { \# zero: } 15[9] \\
(16)\end{array}$ & $\begin{array}{c}\text { Imp.: } 25.45 \%[18.42] \\
\# \text { best: } 49[28] \\
\text { \# zero: } 18[12] \\
(24)\end{array}$ & - \\
\hline
\end{tabular}

Table 4: Average performance measures for each smoothing criterion

Finally, the influence of product variety and forecast uncertainty is to be investigated. Figures 1a and 1b display the impact of both factors on average improvement over successive planning. Both increasing product variety and forecast errors enlarge shortterm work overload. This finding is in line with intuition because both factors increase the deviation between the anticipated model-mix applied in medium-term ALB and the daily model-mix occurring in sequencing, so that ALB increasingly operates on "wrong" data. In both figures only four selected smoothing criteria are displayed (one for each column in Table 2; missing criteria exhibit very similar curves). Apparently, solutions 
suffer more from high product variety than increasing forecast errors. This is because high product variety automatically entails increasing forecast errors. When there are a lot of models which all are very unlikely to be produced during a day or shift the least bit of uncertainty can have huge effects. For instance, assume that according to the model mix a demand of 0.5 units per shift of model $m$ is expected. This is not a very useful piece of information, since in any given shift the model will either be in demand or not, but half a unit of model $m$ will definitely not be assembled. These "rounding errors" are less significant when the expected demands per model are higher, which only happens under low product variety.

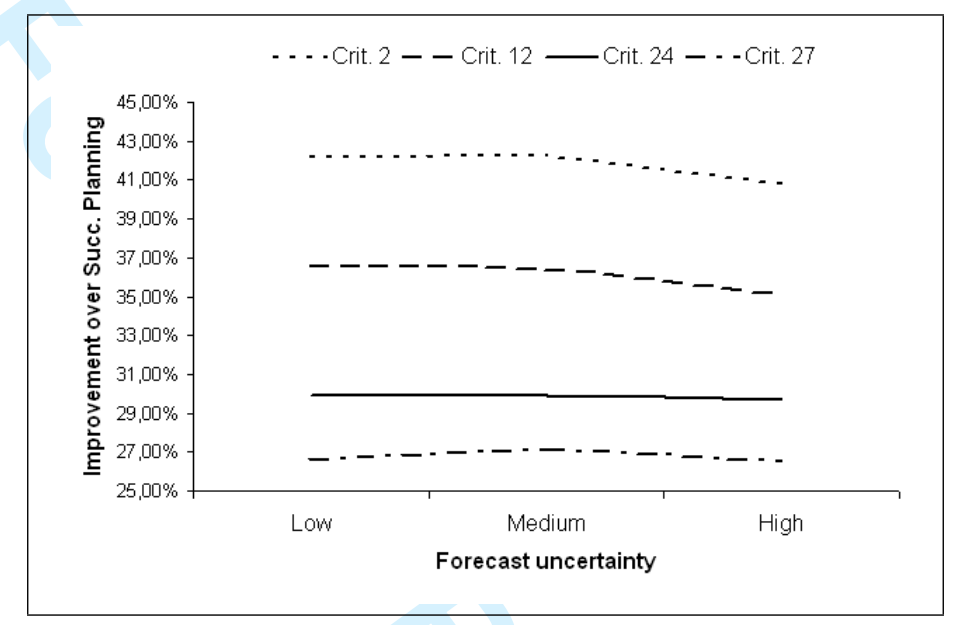

(a) The effects of forecast uncertainty

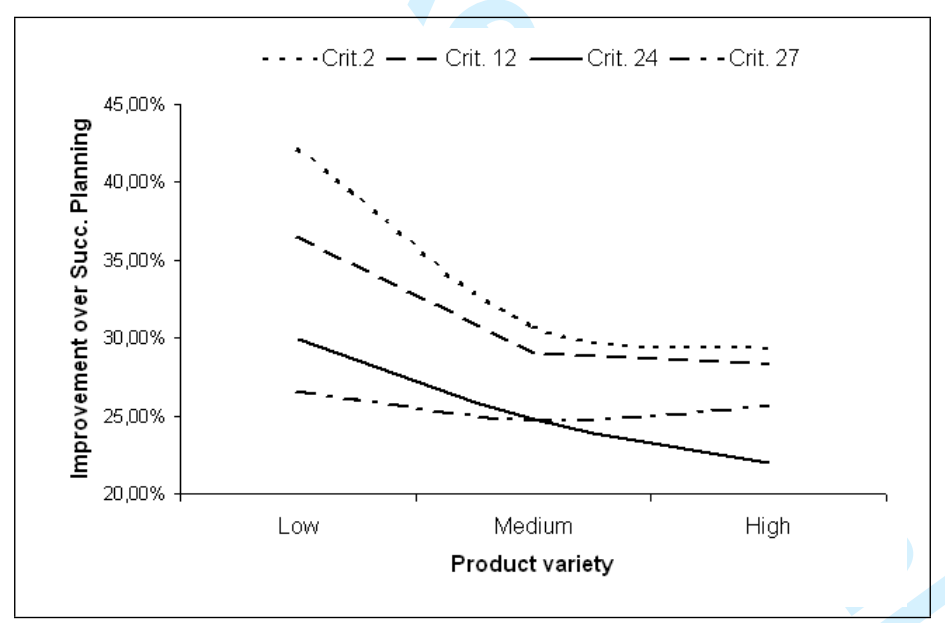

(b) The effects of product variety

Figure 1: The average performance of four criteria

More detailed figures about the influence of product variety and forecast errors are provided by Table 5 . This table lists the reduction of work overload compared to successive 
planning for each criterion, first under low product variety and low forecast uncertainty (labeled L/L), second under low variety and high uncertainty (labeled HU), third under low uncertainty and high variety (labeled HV) and, finally, under high variety and forecast uncertainty (labeled $\mathrm{H} / \mathrm{H}$ ). Obviously, vertical balancing (Column D) suffers far less when there are lots of models to choose from than the horizontal balancing criteria (Columns A through C). This is logical, seeing that these objectives concern themselves only with average capacity demands - which do not depend on the number of models. This is not the case when horizontal balancing is applied: Model-specific information is central to these objectives but grows increasingly unreliable under high variety and uncertainty.

Table 5 also allows a meaningful comparison of weighted with unweighted criteria. Considering only the values obtained under low forecast uncertainty and low variety, regardless of column weighting is always better than not weighting, except when the maximum divergence distance measure is used, where results are ambiguous. This advantage vanishes when either forecast errors or product variety (or both) rise. All in all, while all criteria lose ground when demands become more volatile and some suffer more than others, the ranking stays basically the same: in general, column A is still best, column D is still worst and they all are still a lot better than the unimproved successive planning solutions.

In conclusion, no single criterion delivers the best results in every instance. However, some clear guidelines can be given:

- as long as there is no extreme product variety, horizontal balancing is superior to vertical balancing

- among the horizontal balancing criteria, those of Column A are usually superior to the others

- minimize the maximum divergence is usually the worst distance measure

- when demands are more or less certain, i.e., there is a reduced product variety and trustworthy forecasts, it is better to weight the criteria with the expected demand portion, irrespective of which criterion is eventually chosen

- the less certain demand forecasts are, the less well horizontal balancing works

All things considered, criteria (1), (2) and (4) work best. The average improvement over successive planning is greatest overall as well as under high product variety and forecast uncertainty. They found the best solution in the most instances and were the most successful in reducing work overload to zero. These findings are in line with those of Domschke et al. (1996) who found criterion (1) to clearly outperform (12), (14) and (15). That being said, each and every of the tested criteria was capable of greatly reducing work overloads. Taking into account that the study showed that horizontal balancing becomes increasingly difficult with rising product diversity, at some point vertical balancing might actually be a better idea. If the number of variants is so great that per-model information becomes virtually meaningless, the average capacity 
demands that the criteria of Column D observe might still be viable, as the graphs in Figure 1b suggest.

\begin{tabular}{|c|c|c|c|c|c|}
\hline & & $\begin{array}{l}\text { Processing time of } \\
\text { model vs. cycle time } \\
\text { (A) }\end{array}$ & $\begin{array}{l}\text { Processing time of } \\
\text { model vs. } \varnothing \\
\text { processing time of } \\
\text { model per station }(\mathrm{B})\end{array}$ & $\begin{array}{l}\text { Processing time of } \\
\text { model vs. } \varnothing \\
\text { processing time of all } \\
\text { models per station (C) }\end{array}$ & $\begin{array}{l}\varnothing \text { Station time vs. } \varnothing \\
\text { processing time of all } \\
\text { models per station (D) }\end{array}$ \\
\hline \multirow{2}{*}{ 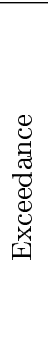 } & 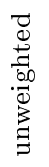 & $\begin{array}{l}\text { L/L: } 39.83 \%[34.10] \\
\text { HU: } 38.56 \%[34.39] \\
\text { HV: } 28.93 \%[26.69] \\
\text { H/H: } 29.34 \%[27.67] \\
\text { (1) }\end{array}$ & $\begin{array}{l}\text { L/L: } 35.84 \%[31.95] \\
\text { HU: } 34.55 \%[30.50] \\
\text { HV: } 28.12 \%[26.41] \\
\text { H/H: } 28.27 \%[26.69] \\
\qquad 9)\end{array}$ & \begin{tabular}{l} 
L/L: $34.98 \%[31.64]$ \\
HU: $33.77 \%[31.28]$ \\
HV: $27.71 \%[25.75]$ \\
H/H: $27.81 \%[26.28]$ \\
\multicolumn{1}{c}{$(17)$}
\end{tabular} & $\begin{array}{l}\text { L/L: } 28.68 \%[24.85] \\
\text { HU: } 27.90 \%[24.60] \\
\text { HV: } 28.05 \%[24.64] \\
\text { H/H: } 28.11 \%[24.95] \\
(25)\end{array}$ \\
\hline & 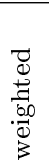 & $\begin{array}{l}\text { L/L: } 42.18 \%[36.19] \\
\text { HU: } 40.81 \%[35.22] \\
\text { HV: } 29.28 \%[26.77] \\
\text { H/H: } 28.97 \%[26.64] \\
\quad(2)\end{array}$ & $\begin{array}{l}\text { L/L: } 36.41 \%[32.17] \\
\text { HU: } 34.60 \%[31.06] \\
\text { HV: } 28.43 \%[26.32] \\
\text { H/H: } 28.71 \%[26.67] \\
\quad(10)\end{array}$ & $\begin{array}{l}\text { L/L: } 37.18 \%[33.38] \\
\text { HU: } 35.42 \%[33.29] \\
\text { HV: } 28.04 \%[25.89] \\
\text { H/H: } 28.22 \%[26.09] \\
\qquad(18)\end{array}$ & - \\
\hline \multirow{2}{*}{ 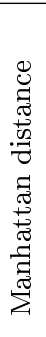 } & 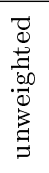 & $\begin{array}{l}\text { L/L: } 37.89 \%[34.02] \\
\text { HU: } 36.38 \%[32.63] \\
\text { HV: } 28.55 \%[26.76] \\
\text { H/H: } 28.73 \%[27.24] \\
\quad(3)\end{array}$ & $\begin{array}{l}\text { L/L: } 35.84 \%[31.80] \\
\text { HU: } 34.88 \%[31.56] \\
\text { HV: } 27.79 \%[26.29] \\
\text { H/H: } 28.07 \%[26.99] \\
(11)\end{array}$ & $\begin{array}{l}\text { L/L: } 34.91 \%[31.63] \\
\text { HU: } 33.75 \%[30.21] \\
\text { HV: } 27.53 \%[25.71] \\
\text { H/H: } 27.90 \%[26.35] \\
(19)\end{array}$ & $\begin{array}{l}\text { L/L: } 27.71 \%[25.47] \\
\text { HU: } 25.58 \%[24.19] \\
\text { HV: } 25.89 \%[24.48] \\
\text { H/H: } 25.99 \%[24.98] \\
(26)\end{array}$ \\
\hline & 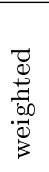 & $\begin{array}{l}\text { L/L: } 40.18 \%[36.24] \\
\text { HU: } 37.93 \%[34.72] \\
\text { HV: } 28.86 \%[26.78] \\
\text { H/H: } 29.15 \%[27.24] \\
\quad(4)\end{array}$ & \begin{tabular}{l} 
L/L: $36.54 \%[32.43]$ \\
HU: $35.14 \%[31.91]$ \\
HV: $28.30 \%[26.46]$ \\
H/H: $28.38 \%[26.70]$ \\
\multicolumn{1}{c}{$(12)$}
\end{tabular} & $\begin{array}{l}\text { L/L: } 36.90 \%[33.40] \\
\text { HU: } 36.05 \%[33.48] \\
\text { HV: } 27.79 \%[25.68] \\
\text { H/H: } 27.75 \%[25.93] \\
(20)\end{array}$ & - \\
\hline \multirow{2}{*}{ 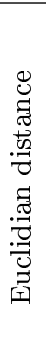 } & 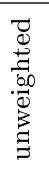 & $\begin{array}{l}\text { L/L: } 36.51 \%[33.22] \\
\text { HU: } 34.93 \%[31.36] \\
\text { HV: } 27.85 \%[26.52] \\
\text { H/H: } 27.95 \%[26.53] \\
\quad(5)\end{array}$ & $\begin{array}{l}\text { L/L: } 36.45 \%[33.28] \\
\text { HU: } 35.18 \%[30.77] \\
\text { HV: } 27.92 \%[26.61] \\
\text { H/H: } 28.01 \%[27.01] \\
(13)\end{array}$ & $\begin{array}{l}\text { L/L: } 36.47 \%[33.35] \\
\text { HU: } 34.49 \%[32.34] \\
\text { HV: } 28.01 \%[26.72] \\
\text { H/H: } 28.18 \%[27.06] \\
\qquad(21)\end{array}$ & $\begin{array}{l}\text { L/L: } 26.61 \%[26.22] \\
\text { HU: } 26.48 \%[26.25] \\
\text { HV: } 25.64 \%[24.17] \\
\text { H/H: } 25.47 \%[24.05] \\
\qquad(27)\end{array}$ \\
\hline & 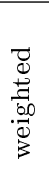 & $\begin{array}{l}\text { L/L: } 37.12 \%[34.12] \\
\text { HU: } 34.84 \%[33.03] \\
\text { HV: } 24.73 \%[20.18] \\
\text { H/H: } 25.07 \%[20.94] \\
\qquad(6)\end{array}$ & $\begin{array}{l}\text { L/L: } 37.13 \%[34.18] \\
\text { HU: } 36.98 \%[35.05] \\
\text { HV: } 24.12 \%[18.80] \\
\text { H/H: } 23.92 \%[18.64] \\
\qquad(14)\end{array}$ & $\begin{array}{c}\text { L/L: } 37.20 \%[34.21] \\
\text { HU: } 36.32 \%[33.54] \\
\text { HV: } 23.99 \%[18.73] \\
\text { H/H: } 24.18 \%[18.72] \\
(22)\end{array}$ & - \\
\hline \multirow{2}{*}{ 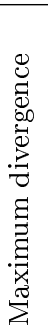 } & 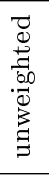 & $\begin{array}{l}\text { L/L: } 23.12 \%[17.83] \\
\text { HU: } 22.94 \%[18.60] \\
\text { HV: } 19.92 \%[16.03] \\
\text { H/H: } 19.35 \%[15.30] \\
\quad(7)\end{array}$ & \begin{tabular}{l} 
L/L: $31.49 \%[24.04]$ \\
HU: $29.37 \%[21.84]$ \\
HV: $24.16 \%[19.99]$ \\
H/H: $24.18 \%[19.72]$ \\
\multicolumn{1}{c}{$(15)$}
\end{tabular} & \begin{tabular}{l} 
L/L: $29.06 \%[24.31]$ \\
HU: $27.46 \%[23.01]$ \\
HV: $23.39 \%[19.85]$ \\
H/H: $23.09 \%[19.90]$ \\
\multicolumn{1}{c}{$(23)$}
\end{tabular} & $\begin{array}{l}\text { L/L: } 25.71 \%[20.77] \\
\text { HU: } 24.59 \%[18.76] \\
\text { HV: } 27.52 \%[22.38] \\
\text { H/H: } 27.10 \%[21.91] \\
\qquad(28)\end{array}$ \\
\hline & 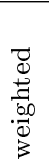 & $\begin{array}{l}\text { L/L: } 23.76 \%[14.97] \\
\text { HU: } 21.46 \%[12.60] \\
\text { HV: } 19.89 \%[15.75] \\
\text { H/H: } 19.72 \%[15.89] \\
\quad(8)\end{array}$ & $\begin{array}{l}\text { L/L: } 31.14 \%[21.46] \\
\text { HU: } 30.81 \%[21.49] \\
\text { HV: } 23.04 \%[18.18] \\
\text { H/H: } 23.23 \%[18.44] \\
\quad(16)\end{array}$ & $\begin{array}{l}\text { L/L: } 29.94 \%[19.54] \\
\text { HU: } 29.67 \%[20.68] \\
\text { HV: } 21.99 \%[15.98] \\
\text { H/H: } 21.93 \%[15.83] \\
(24)\end{array}$ & - \\
\hline
\end{tabular}

Table 5: Performance under high/low forecast errors and product variety

\section{Conclusions}

The paper on hand investigates the anticipation of short-term sequencing issues by workload smoothing during medium-term line balancing. After introducing 28 different forms of anticipation mechanisms, all of them are tested in a comprehensive computational 
study. The results show that workload smoothing in general is always better than ignoring the interdependencies between both planning tasks when executing them successively. Furthermore, promising smoothing criteria among the 28 investigated are identified and the impact of product variety and forecast errors is tested. However, there remain multiple challenges for future research:

- Our computational study presupposed a basic assembly line setting to identify elementary interdependencies between ALB and sequencing. However, it would be a valuable contribution to test the impact of workload smoothing in more complex settings, e.g., incorporating open station borders or parallel line segments, the impact of line stoppage or more complex primary ALB objective functions.

- Moreover, it would be interesting to compare workload smoothing with simultaneous planning. However, such a comparison requires the determination of a reliable and representative model-mix simultaneous balancing and sequencing is executed on, which remains a yet unsolved problem.

- Finally, another problem remains, when product variety reaches dimensions of modern automobile assembly lines with billions of possible models. In these dimensions of product variety there is no adequate basis for estimating future demand rates. Instead, reliable estimations can be provided only for the frequency of option occurrences over all models (option-mix), e.g., the percentage of cars equipped with air conditioning (see Röder and Tibken, 2006). Moreover, an ALB procedure for workload smoothing, which has to iterate through all possible models, suffers from the extraordinary computational requirements in this order of magnitude. Consequently, workload smoothing is to be altered to account for this fundamental change in information and the stations' workload is to be assigned to options. An analogous procedure is provided by Boysen et al. (2006) for generating joint precedence graphs.

All these challenges seem to be valuable fields of future research because workload smoothing at an early stage during ALB considerably eases and improves short-term assembly line operations.

\section{References}

Agnetis, A.; Ciancimino, A.; Lucertini, M.; Pizzichella, M. (1995): Balancing flexible lines for car components assembly. International Journal of Production Research 33, $333-350$.

Ajenblit, D.A.; Wainwright, R.L. (1998): Applying genetic algorithms to the U-shaped assembly line balancing problem. In: IEEE World Congress on Computational Intelligence Proceedings, 96-101.

Bard, J.F.; Dar-El, E.; Shtub, A. (1992): An analytic framework for sequencing mixed model assembly lines. International Journal of Production Research 30, 35-48. 
Baybars, I. (1986): A survey of exact algorithms for the simple assembly line balancing problem. Management Science 32, 909-932.

Becker, Ch.; Scholl, A. (2006): A survey on problems and methods in generalized assembly line balancing. European Journal of Operational Research 168, 694-715.

Bhattacharjee, T.K., Sahu, S., 1987. A heuristic approach to general assembly line balancing. International Journal of Operations and Production Management 8, 67-77.

Bock, S.; Rosenberg, O.; van Brackel, T. (2006): Controlling mixed-model assembly lines in real-time by using distributed systems. European Journal of Operational Research $168,880-904$.

Boysen, N. (2005): Reihenfolgeplanung bei Variantenflieffertigung: Ein integrativer Ansatz. ZfB Zeitschrift für Betriebswirtschaft 75, 135-156.

Boysen, N.; Fliedner, M.; Scholl, A. (2006): Assembly line balancing: Joint precedence graphs under high product variety. IIE Transactions (to appear).

Boysen, N.; Fliedner, M.; Scholl, A. (2007a): Production Planning of Mixed-Model Assembly Lines: Overview and Extensions. Jenaer Schriften zur Wirtschaftswissenschaft 06/07, University of Jena.

Boysen, N.; Fliedner, M.; Scholl, A. (2007b): A classification of assembly line balancing problems. European Journal of Operational Research 183, 674-693.

Boysen, N.; Fliedner, M.; Scholl, A. (2009): Sequencing mixed-model assembly lines: Survey, classification and model critique. European Journal of Operational Research 192, 349-373.

Bukchin, J. (1998): A comparative study of performance measures for throughput of a mixed model assembly line in a JIT environment. International Journal of Production Research 36, 2669-2685.

Cho, H.-S.; Paik, C.-H.; Yoon, H.-M.; Kim, H.-G. (2005): A robust design of simulated annealing approach for mixed-model sequencing. Computers \& Industrial Engineering $48,753-764$.

Chopra, S.; Meindl, P. (2006): Supply Chain Management, 3rd edition. Prentice Hall, Upper Saddle River, NJ.

Decker, M. (1993): Capacity smoothing and sequencing for mixed-model lines. International Journal of Production Economics 30-31, 31-42.

Domschke, W.; Klein, R.; Scholl, A. (1996): Antizipative Leistungsabstimmung bei moderner Variantenfließfertigung. ZfB Zeitschrift für Betriebswirtschaft 66, 1465-1490.

Kim, Y. K.; Kim, J. Y.; Kim, Y. (2000a): A coevolutionary algorithm for balancing and sequencing in mixed model assembly lines. Applied Intelligence 13, 247-258. 
Kim, Y. K.; Kim, S. J.; Kim, J. Y. (2000b): Balancing and sequencing mixedmodel Ulines with a co-evolutionary algorithm. Production Planning \& Control 11, 754-764.

Kim, Y. K.; Kim, J. Y.; Kim, Y. (2006): An endosymbiotic evolutionary algorithm for the integration of balancing and sequencing in mixed-model U-lines. European Journal of Operational Research 168, 838-852.

Lundy, M.; Mees, A. (1986): Convergence of an annealing algorithm. Mathematical Programming 34, 111-124.

Matanachai, S.; Yano, C.A. (2001): Balancing mixed-model assembly lines to reduce work overload. IEE Transactions 33, 29-42.

McMullen, P.R.; Frazier, G.V. (1997): A heuristic for solving mixed-model line balancing problems with stochastic task durations and parallel stations. International Journal of Production Economics 51, 177-190.

McMullen, P. R.; Frazier, G. V. (1998): Using simulated annealing to solve a multiobjective assembly line balancing problem with parallel workstations. International Journal of Production Research 36, 2717-2741.

McMullen, P. R.; Frazier, G. V. (2000): A simulated annealing approach to mixedmodel sequencing with multiple objectives on a just-in-time line. IIE Transactions 32, $679-686$.

McMullen, P.R.; Tarasewich, P. (2003): Using ant techniques to solve the assembly line balancing problem. IIE Transactions 35, 605-617.

McMullen, P.R.; Tarasewich, P. (2006): Multi-objective assembly line balancing via a modified ant colony optimization technique. International Journal of Production Research 44, 27-42.

Merengo, C.; Nava, F.; Pozetti, A. (1999): Balancing and sequencing manual mixedmodel assembly lines. International Journal of Production Research 37, 2835-2860.

Meyr, H. (2004): Supply chain planning in the German automotive industry. OR Spectrum 26, 447-470.

Miltenburg, J. (2002): Balancing and scheduling mixed-model U-shaped production lines. International Journal of Flexible Manufacturing Systems 14, 119-151.

Moodie, C.L.; Young, H.H. 1965. A heuristic method of assembly line balancing for assumptions of constant or variable work element times. Journal of Industrial Engineering $16,23-29$.

Pastor, R.; Corominas, A. (2000): Assembly line balancing with incompatibilities and bounded workstation loads. Ricerca Operativa 30, 23-45. 
Pinnoi, A.; Wilhelm, W.E. (1997): A branch and cut approach for workload smoothing on assembly lines. INFORMS Journal on Computing 9, 335-350.

Ponnambalam, S.G.; Aravindan, P.; Naidu, G.M. (2000): A multiobjective genetic algorithm for solving assembly line balancing problem. International Journal of Advanced Manufacturing Technology 16, 341-352.

Rachamadugu, R.; Talbot, B. (1991): Improving the equality of workload assignments in assembly lines. International Journal of Production Research 29, pp. 619-633.

Rekiek, B.; De Lit, P.; Pellichero, F.; L'Eglise, T.; Fouda, P.; Falkenauer, E.; Delchambre, A. (2001): A multiple objective grouping genetic algorithm for assembly line design. Journal of Intelligent Manufacturing 12, 467-485.

Rekiek, B.; de Lit, P.; Delchambre, A. (2002): Hybrid assembly line design and user's preferences. International Journal of Production Research 40, 1095-1111.

Röder, A.; Tibken, B. (2006): A methodology for modeling inter-company supply chains and for evaluating a method of integrated product and process documentation. European Journal of Operational Research 169, 1010-1029.

Sabuncuoglu, I.; Erel, E.; Tanyer, M.; (2000): Assembly line balancing using genetic algorithms. Journal of Intelligent Manufacturing 11, 295-310.

Sarker, B.R.; Shanthikumar, J.G. (1983): A generalized approach for serial or parallel line balancing. International Journal of Production Research 21, 109-133.

Sawik, T. (2002): Monolithic vs. hierarchical balancing and scheduling of a flexible assembly line. European Journal of Operational Research 143, 115-124.

Scholl, A.; Klein, R. (1997): SALOME: A Bidirectional Branch-And-Bound Procedure for Assembly Line Balancing. INFORMS Journal on Computing 9, 319-334.

Scholl, A.; Klein, R.; Domschke, W. (1998): Pattern based vocabulary building for effectively sequencing mixed-model assembly lines. Journal of Heuristics 4, 359-381.

Scholl, A.; Klein, R. (1999): Balancing assembly lines effectively - A computational comparison. European Journal of Operational Research 114, 50-58.

Scholl, A. (1999): Balancing and sequencing assembly lines, 2nd edition. Physica, Heidelberg.

Scholl, A.; Becker, Ch. (2006): State-of-the-art exact and heuristic solution procedures for simple assembly line balancing. European Journal of Operational Research 168, 666-693.

Sparling, D.; Miltenburg, J. (1998): The mixed-model U-line balancing problem. International Journal of Production Research 36, 485-501. 
Suresh, G.; Sahu, S. (1994): Stochastic assembly line balancing using simulated annealing. International Journal of Production Research 32, 1801-1810.

Suresh, G.; Vinod, V.V.; Sahu, S. (1996): Genetic algorithm for assembly line balancing. Production Planning and Control 7, 38-46.

Talbot, F.B.; Patterson, J.H.; Gehrlein, W.V. (1986): A comparative evaluation of heuristic line balancing techniques. Management Science 32, 430-454.

Thomopoulos, N.T. (1970): Mixed model line balancing with smoothed station assignments. Management Science 16, 593-603.

Tsai, H.-L. (1995): Mixed-model Sequencing to Minimize Utility Work and the Risk of Conveyor Stoppage. Management Science 41, 485-495.

Ugurdag, H.F.; Rachamadugu, R.; Papachristou, C.A. (1997): Designing paced assembly lines with fixed number of stations. European Journal of Operational Research 102, 488-501.

Vilarinho, P.M.; Simaria, A.S. (2002): A two-stage heuristic method for balancing mixedmodel assembly lines with parallel workstations. International Journal of Production Research 40, 1405-1420.

Vilarinho, P.M.; Simaria, A.S. (2006): ANTBAL: An ant colony optimization algorithm for balancing mixed-model assembly lines with parallel workstations. International Journal of Production Research 44, 291-303.

Yano, C.A.; Rachamadugu, R. (1991): Sequencing to minimize work overload in assembly lines with product options. Management Science 37, 572-586. 